\title{
Median Nerve Parachordoma Masquerading Schwannoma: An Uncommon Case
}

\author{
Sumit Bansal ${ }^{1}$ Pritinanda Mishra ${ }^{2}$ Mamita Nayak² \\ ${ }^{1}$ Department of Neurosurgery, All India Institute of Medical \\ Sciences, Bhubaneswar, Orissa, India \\ 2Department of Pathology and Lab Medicine, All India Institute of \\ Medical Sciences, Bhubaneswar, Orissa, India
}

Indian J Neurosurg 2019;8:145-146

Benign tumors involving peripheral nerves of the upper extremity are uncommon. An entrapment syndrome resulting from the growing tumor causes symptoms. Pain is the most common complaint. We present a rare case of a median nerve parachordoma, a rare type of a benign tumor that presents as a palpable and painful mass on the flexor aspect of the forearm.

A 62-year-old woman presented with a painful swelling at the flexor aspect of the right forearm. On clinical examination, there was a painful solid mass, which was $2 \mathrm{~cm}$ in length, little sensitive to pressure, and had mobility restriction in both transverse and longitudinal directions. Percussion over the mass produced a Tinel's-like sensation along the median nerve. The patient experienced mild numbness in the distribution of the median nerve in the palm, but no motor weakness or muscle atrophy was noticed.

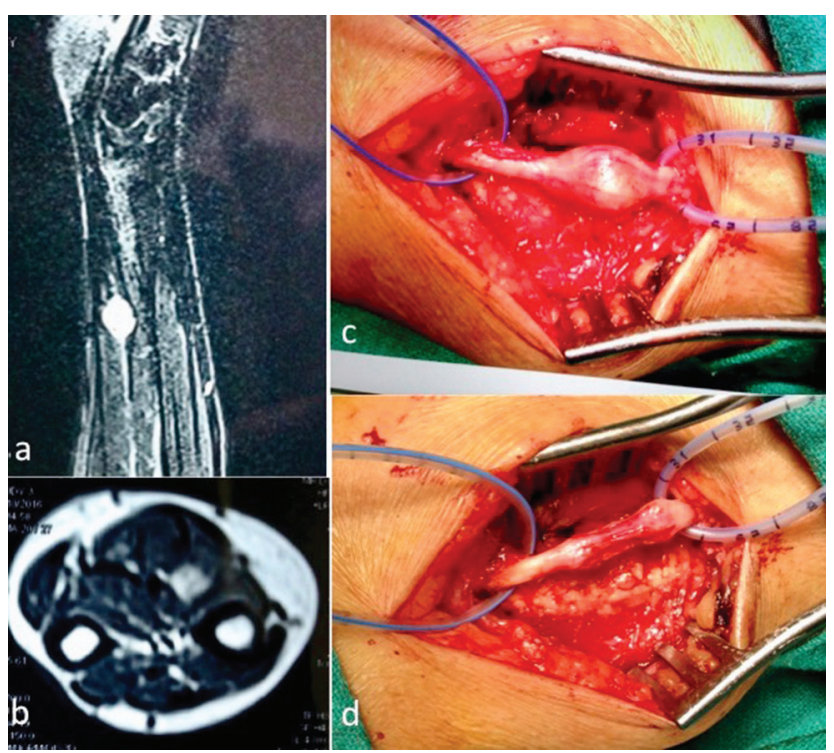

Fig. $1 \mathrm{MRI}$ examination of right forearm showed contrast-enhancing lesion deep to the flexor tendon of forearm $(\mathbf{a}, \mathbf{b})$. The tumor was arising from the median nerve in the right forearm, below the flexor tendon of forearm (c). The mass was encapsulated and removed totally (d).

\section{Rabi Sahu $^{1} \quad$ Ashis Patnaik ${ }^{1}$}

Address for correspondence Sumit Bansal, MCh, Assistant Professor, Room No. 419, Department of Neurosurgery, All India Institute of Medical Sciences, Bhubaneswar, Orissa 751019, India (e-mail: drsumitbansal@gmail.com).

On magnetic resonance imaging (MRI) examination, lesion had a relatively homogenous low signal, slightly lower to the flexor tendon of the forearm, on T1-weighted images. On T1 fat-suppressed contrast images, increased gadolinium enhancement was noticed ( $\mathbf{- F i g}$. 1a, $\mathbf{b})$. Based on the clinical and MRI features, provisional diagnosis of a nerve sheath tumor arising from the median nerve was made.

A longitudinal incision centered over the tumor bulk at the distal part of flexor aspect of right forearm was performed. Adequate exposure of the nerve was done, both proximal and distal to the tumor. On exploration, the tumor was found to arise from the median nerve in the right forearm, below the flexor tendon. The tumor had an eccentric position and was firmly attached to the median nerve. The epineurium was longitudinally incised, and the soft tumor mass was dissected from surrounding nerve fascicles. The mass was encapsulated and removed completely ( $\mathbf{- \text { Fig. }} \mathbf{1 c}$, d). Postoperative course was uneventful with no new neurologic deficit. The histopathology report was suggestive of parachordoma ( - Fig. 2). At 1-month follow-up, the wound was healed with no new symptoms.

Parachordomas (or myoepitheliomas) are rare soft tissue tumors with approximately 100 cases reported, ${ }^{1}$ with

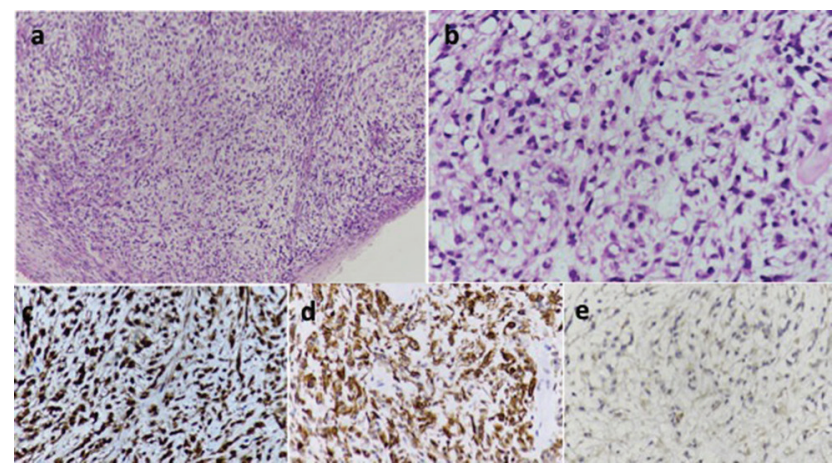

Fig. 2 (a) Epithelioid cells and spindle cells lying in myxoid stroma (H\&E 100X). (b) Epithelioid cells with clear cytoplasm (H\&E 400X). (c-e) Tumor cells are immunopositive for S-100, cytokeratin, and negative for P53 (IHC 400X). received

July 25, 2017

accepted after revision

November 22, 2017

published online

August 23, 2019
DOI https://doi.org/

$10.1055 / \mathrm{s}-0039-1694840$

ISSN 2277-954X.
(C2019 Neurological Surgeons'

Society of India
License terms

(1) $\Theta \circledast$ 
Table 1 Published literature of upper limb parachordoma cases

\begin{tabular}{|c|c|c|c|c|c|c|c|}
\hline Case No. & $\begin{array}{l}\text { Age } \\
\text { (y) }\end{array}$ & Sex & Site & Recurrence & Metastasis & Fatal & Authors (y) \\
\hline 1 & 12 & Male & Arm & No & No & No & \multirow{3}{*}{ Dabska (1977) } \\
\hline 2 & 22 & Female & Forearm & No & No & No & \\
\hline 3 & 28 & Female & Finger & $2 y$ & No & No & \\
\hline 4 & 25 & Male & Finger & Unknown & Unknown & No & Sangueza and White (1994) \\
\hline 5 & 45 & Female & Palm & $3 \mathrm{mo}$ & No & No & Niezabitowski et al. (1995) \\
\hline 6 & 25 & Female & Triceps & No & No & No & \multirow{2}{*}{ Fisher and Miettinen (1997) } \\
\hline 7 & 14 & Male & Wrist & Unknown & Unknown & No & \\
\hline 8 & 25 & Female & Forearm & Yes & No & No & Imlay et al. (1998) \\
\hline 9 & 42 & Female & Forearm & No & No & No & \multirow{2}{*}{ Folpe et al. (1999) } \\
\hline 10 & 38 & Male & Deltoid & No & No & No & \\
\hline 11 & 20 & Female & Hand & No & No & No & Separovic et al. (2001) \\
\hline 12 & 60 & Female & Arm & No & No & No & Clabeaux et al. (2008) \\
\hline 13 & 6 & Female & Forearm & No & Yes & No & Guedes et al. (2009) \\
\hline 14 & 76 & Male & Hand & $2 y$ & No & No & Bell et al. (2009) \\
\hline 15 & 31 & Male & Wrist & $1 \mathrm{mo}$ & No & No & Fulciniti et al. (2011) \\
\hline 16 & 67 & Female & Arm & No & Yes & No & De Comas et al. (2011) \\
\hline 17 & 28 & Male & Shoulder & $1 \mathrm{y}$ & Unknown & No & Karakaya et al. (2011) \\
\hline 18 & 44 & Male & Index finger & No & No & No & Ali et al. (2012) \\
\hline 19 & 32 & Male & Arm & No & No & No & Estrems Diaz et al. (2013) \\
\hline
\end{tabular}

19 cases in upper limbs till date ${ }^{2,3}$ (-Table 1 ). They have an indolent nature with a male predilection, typically occurring in the fourth decade of life and usually in the extremities. ${ }^{2}$ There have been reports regarding late recurrence and metastasis. ${ }^{4}$ Parachordoma was originally believed to be a chordoma occurring in nonaxial sites, but now it is considered as a unique entity. ${ }^{5}$ The management for these lesions is wide surgical excision, with clinical and imaging follow-up to exclude recurrence.

Other differential diagnosis was schwannoma, which is more commonly seen than parachordoma. They are usually solitary and benign lesions. Schwannomas can be asymptomatic or can produce pain, a positive Tinel's sign or a Tinel's-like sensation, and sensory symptoms. The slow growth pattern of benign nerve tumors allows for adaptation of the nerve function to the pressure effects. ${ }^{6}$ Schwannomas share many features with other soft tissue tumors and are frequently misdiagnosed due to similarities.

Tumors of the median nerve are diagnostically challenging and median nerve parachordoma is rare as compared with schwannoma. The diagnosis is made only through histopathology. Parachordoma should be included in differential diagnosis of soft tissue tumor arising in the forearm, especially arising from the median nerve.

\section{Financial Support}

None.

\section{Conflicts of Interest}

None.

\section{References}

1 De Comas AM, Deavers MT, Raymond AK, Madewell JE, Lewis VO. Intraneural parachordoma of the arm with regional metastases. Skeletal Radiol 2011;40(7):943-946

2 Clabeaux J, Hojnowski L, Valente A, Damron TA. Case report: parachordoma of soft tissues of the arm. Clin Orthop Relat Res 2008;466(5):1251-1256

3 Gao HX, Liu CX, Zou H, et al. Parachordoma/myoepithelioma of the kidney: first report of a myxoid mimicry in an unusual location. Int J Clin Exp Pathol 2014;7(3):1258-1265

4 Fisher C, Miettinen M. Parachordoma: a clinicopathologic and immunohistochemical study of four cases of an unusual soft tissue neoplasm. Ann Diagn Pathol 1997;1(1):3-10

5 Kinoshita G, Yasoshima H. Fatal parachordoma. J Orthop Sci 2007;12(1):101-106

6 Ogose A, Hotta T, Morita T, et al. Tumors of peripheral nerves: correlation of symptoms, clinical signs, imaging features, and histologic diagnosis. Skeletal Radiol 1999;28(4):183-188 